\title{
Urinary Incontinence in Women Living in Rural Areas and Reflections on Quality of Life
}

\author{
Zerrin Gamsizkan $^{1(\mathrm{ID})}$, Mehmet Ali Sungur ${ }^{2}(\mathrm{ID})$, Aski Ellibes Kaya ${ }^{3(\mathrm{ID})}$, Yasemin Cayir ${ }^{4(\mathrm{ID})}$ \\ ${ }^{1}$ Department of Family Medicine, Medical Faculty, Duzce University, Duzce, Turkey \\ ${ }^{2}$ Department of Biostatistics and Medical Informatics, Medical Faculty, Duzce University, Duzce, Turkey \\ ${ }^{3}$ Department of Obstetrics and Gynecology, Medical Faculty, Duzce University, Duzce, Turkey \\ ${ }^{4}$ Department of Family Medicine, Medical Faculty, Atatürk University, Erzurum, Turkey
}

Copyright@ Author(s) - Available online at https://dergipark.org.tr/en/pub/mbsjohs Content of this journal is licensed under a Creative Commons Attribution-NonCommercial 4.0 International License,

Received: 06 December 2020, Accepted: 29 March 2021, Published online: 30 April 2021

(C) Ordu University Institute of Health Sciences, Turkey, 2021

\begin{abstract}
Objective: Urinary incontinence (UI) is a health problem affecting women's quality of life. Since it is not a life-threatening disease, women with urinary incontinence usually do not seek treatment in this regard. This causes them not to benefit from treatment opportunities that will improve their lives. The study aims to investigate the UI status in women living in rural areas and to determine its reflection on the quality of life. Methods: A total of 589 patients were included in the study. The data was collected with a questionnaire including socio-demographic characteristics questions along with the Urogenital Distress Inventory (UDI-6) scale and the Incontinence Impact Questionnaire (IIQ-7).

Results: 157 (26.7\%) patients who participated in our study suffered from UI. 70 (44.6\%) of these patients suffered from stress incontinence (SUI), 40 (25.5\%) were urge incontinence (UUI) and 47 (29.9\%) were mixed incontinence (MUI). BMI, constipation, and menopause were found to be aggravating factors for incontinence $(\mathrm{p}<0,001)$. According to the UDI-6 scale; MUI significantly impacts a woman's life quality followed by urge or stress incontinence $(\mathrm{p}<0,001)$. Stress incontinence decreases life quality more than urge incontinence $(\mathrm{p}<0,001)$ based on the IIQ-7 scale.

Conclusion: Despite the high frequency of female urinary incontinence, many patients cannot easily express this distress. Family physicians to whom the patient applies most frequently should question their patients about UI and direct their patients to appropriate treatment.
\end{abstract}

Key words: Urinary incontinence, UDI-6, IIQ-7, Quality of life, Womens' health

Suggested Citation: Gamsizkan Z, Sungur MA, Ellibes Kaya A, Cayir Y. Urinary incontinence in women living in rural areas and reflections on quality of life. Mid Blac Sea J Health Sci, 2021; 7(1):32-37

\section{Address for correspondence/reprints:}

Zerrin Gamsizkan

Telephone number: +90 (380) $5421106-6513$

E-mail: zgamsizkan@yahoo.com

\section{Introduction}

Physicians with a high level of awareness may unveil several diseases that adversely affect the quality of life. One of these diseases is urinary incontinence and it can be diagnosed early by a family physician. Urinary incontinence (UI), according to the definition of the International Community of Incontinence, is defined as "involuntary urinary incontinence that can be shown objectively" (1). Although many prospective longitudinal studies have examined UI in women, either in the general population or focused on pregnancy, menopause, or 
old age, it is a disease that affects female patients that can be seen at every age $(2,3)$. In social studies, 20 $30 \%$ of women are affected by UI, but it is estimated that only $7-12 \%$ of them perceive it as a health problem (3). The prevalence of UI according to some studies performed in our country, is in a various range; $21-37 \%(4,5)$. The reason for such difference in the prevalence of is explained as the diversity of the studied societies; differences in the definition of urinary incontinence and the number of clinical trials (6). Many factors have been described increasing the reasons and prevalence of urinary incontinence. Risk factors for UI; advanced age, hormonal disorders, obesity, birth trauma, genetic disorders, recurrent urinary tract infections, chronic constipation, smoking, gynecological surgery, diabetes, lung diseases, and neurological diseases $(7,8)$. Although $\mathrm{UI}$ is not a life-threatening disease, individuals suffering from this disease have complaints about social and physical activities, hence the quality of their life decreases (9). Today, UI can be treated with various treatment options, but patients who cannot mention their ailments easily are deprived of these treatments. It is recommended that clinicians also question incontinence in their medical history from female patients so that patients can benefit from advanced treatments $(10,11)$.

In this study, it was aimed to determine the prevalence of UI that restricts the lives of women registered in our family health center and to observe how UI affects their life quality. Providing appropriate treatment and counseling services for UI patients identified as a result of interviews with patients was another of our study goals.

\section{Methods}

The study was planned as a cross-sectional study in a family health center. The region where the family health center is located in a rural area. There are 756 women over the age of 18 registered in the family physician's health system. All-female patients who were subjected to care by family health centers over the age of 18 were informed about the purpose of this study. The volunteer women were interviewed faceto-face in the study. In order to gather information, we used a questionnaire that included 26 questions regarding the socio-demographic and obstetric history of the women. Also, it was determined whether it was difficult to visit a doctor because of urinary incontinence, and a few questions to evaluate the association among chronic diseases, constipation, smoking, and daily tea consumption and UI symptoms were also listed in the questionnaire.
All participants were asked if they had UI symptoms or not. A distinctive question was asked in terms of clinical typing of urinary incontinence, including conditions such as coughing and laughing that cause intra-abdominal pressure. In this regard, the stress suffering from this complaint was considered the user interface (SUI). If a patient wets before she can reach the toilet, it is considered as urge urinary incontinence (UUI) and in the presence of both complaints were evaluated as mixed urinary incontinence (MUI). Participants with UI symptoms were examined in terms of the effects of UI symptoms on quality of life. In order to determine the quality of life, Incontinence Effect Questionnaire (IIQ-7) and the Urogenital Discomfort Scale (UDI-6) were used among patients with UI symptoms. Both were developed to assess the effects of quality of life regarding urinary incontinence and validated in many languages $(12,13)$. The UDI- 6 is composed of six items with three subscales. The subscales are; irritative, stress, and obstructive symptoms. IIQ-7 is composed of seven items with four subscales. These subscales include physical activity, travel, social, and emotional health. Each subscale is formed as a Likert scale and ranges from slight to moderate and great. The higher scores show the reduced quality of life and the severity of symptoms.

\section{Statistical analysis}

All analyses were carried out using SPSS v.22 software. Numerical variables are expressed as mean $\pm \mathrm{SD}$ and categorical variables as frequency and percentage. Numerical data was checked for normal distribution. The Student-t test and One-Way ANOVA followed by Tukey post hoc test, and were used for group comparisons. Pearson Chi-Square test was used for categorical variables, and Bonferroni adjusted method was used where column proportions are different. Pearson correlation analysis was performed to investigate the correlation between numerical data. The significance level was considered as $\mathrm{p}<0.05$.

\section{Results}

In total, 589 patients were included in the study. The mean age of the patients participating in the study was $47.47 \pm 14.09$ years. Of these patients, $26.7 \%(\mathrm{n}=$ 157) reported complaints of UI, while $73.3 \%(n=432)$ said they did not have UI symptoms. In total, $25.5 \%$ $(\mathrm{n}=40)$ patients were diagnosed with UUI. $44.6 \%$ $(\mathrm{n}=70)$ patients were diagnosed with SUI and $29.9 \%$ $(\mathrm{n}=47)$ patients were diagnosed with MUI. When it is examined from the point of view of applying and requesting for treatment, it has been detected that in 
total, $43.3 \% \quad(n=68)$ of patients referred to their physicians for UI symptoms and requested treatment.

Pearson correlation analyses showed a significant and positive correlation between body mass index and UI $(r=0.255, \mathrm{p}<0.001)$. Complaints of UI were significantly higher with the presence of incontinence in the family $(p<0.001)$. UI was significantly more frequent in patients with constipation $(\mathrm{p}<0.001)$. The presence of recurrent urinary tract infections also makes UI significantly higher $(p<0.001)$. A significant increase in UI was observed as the number of pregnancies increased $(r=0.365, p<0.001)$. UI was significantly higher when the age of gestation was below 18 years $(\mathrm{p}<0.001)$. UI was more common among participants who had a history of vaginal delivery $(p<0.005)$. The details of comparisons of participants with and without UI can be seen in Table 1.
According to the analysis of the subgroups; with increasing age, MUI is more common than the other subgroups. Compared with frequent urinary tract infections and the SUI/UUI/ MUI subgroup, MUI and SUI showed more association than UUI. (Table 2).

The participants with UI were evaluated in terms of quality of life. Comparisons of the participants with different types of UI are presented in Table 3. Mixed incontinence patients exhibited the least satisfaction in quality of life compared to both urge and stress incontinence in our study. According to UDI-6 total and subscale scores, patients with stress incontinence were in more discomfort than patients with urge incontinence. The same results were obtained with IIQ-7 total and subscales (Table 3).

Table 1. Comparisons of participants with UI (+) and UI (-)

\begin{tabular}{|c|c|c|c|c|}
\hline Characteristics & & $\begin{array}{c}\text { UI (+) } \\
(\mathbf{n}=157)\end{array}$ & $\begin{array}{c}\text { UI (-) } \\
(n=432)\end{array}$ & $p$ value \\
\hline Age (years) & & $56.61 \pm 11.69$ & $44.14 \pm 13.40$ & $<0.001$ \\
\hline \multirow{2}{*}{ UI in the family $n(\%)$} & Yes & $82(52.2)$ & 46(10.6) & \multirow{2}{*}{$<0.001$} \\
\hline & No & $75(47.8)$ & $386(89.4)$ & \\
\hline \multirow{2}{*}{ Constipation n(\%) } & Yes & $73(46.5)$ & $136(31.5)$ & \multirow{2}{*}{$<0.001$} \\
\hline & No & $84(53.5)$ & $296(68.5)$ & \\
\hline \multirow{2}{*}{ Type of delivery n(\%) } & Vaginal delivery & $142(92.2)$ & $292(82.7)$ & \multirow{2}{*}{0.005} \\
\hline & Caesarean section & $12(7.8)$ & $61(17.3)$ & \\
\hline \multirow{2}{*}{ Menopause n(\%) } & Yes & $119(75.8)$ & $142(32.9)$ & \multirow{2}{*}{$<0.001$} \\
\hline & No & $38(24.2)$ & $290(67.1)$ & \\
\hline \multirow{3}{*}{$\begin{array}{l}\text { Urinary infection in a year } \\
\mathrm{n}(\%)\end{array}$} & 1 time & $51(39.5)$ & $137(52.1)$ & \multirow{3}{*}{$<0.001$} \\
\hline & 2 times & $62(48.1)$ & $119(45.2)$ & \\
\hline & $>3$ times & $16(12.4)$ & $7(2.7)$ & \\
\hline \multirow{3}{*}{$\begin{array}{l}\text { The first delivery age } \\
\text { (years) } n(\%)\end{array}$} & $<18$ & $83(53.9)$ & $79(22.4)$ & \multirow{3}{*}{$<0.001$} \\
\hline & $18-34$ & $70(45.5)$ & $265(75.1)$ & \\
\hline & $>34$ & $1(0.6)$ & $9(2.5)$ & \\
\hline BMI $\left(\mathrm{kg} / \mathrm{m}^{2}\right)$ & & $30.85 \pm 4.58$ & $28.15 \pm 4.52$ & $<0.001$ \\
\hline
\end{tabular}

Table 2. Comparisons of participants with SUI, UUI and MUI

\begin{tabular}{lccccc}
\hline & & $\begin{array}{c}\text { UUI } \\
(\mathbf{n}=\mathbf{4 0})\end{array}$ & $\begin{array}{c}\text { SUI } \\
(\mathbf{n = 7 0})\end{array}$ & $\begin{array}{c}\text { MUI } \\
(\mathbf{n = 4 7})\end{array}$ & p value \\
\hline Age & & $51.20 \pm 10.85^{\mathrm{a}}$ & $56.10 \pm 11.18^{\mathrm{a}}$ & $61.96 \pm 11.03^{\mathrm{b}}$ & $<\mathbf{0 . 0 0 1}$ \\
BMI & & $30.51 \pm 3.93$ & $30.80 \pm 4.68$ & $31.21 \pm 5.01$ & 0.773 \\
Menopause, $\mathbf{n}(\boldsymbol{\%})$ & Yes & $25(62.5)$ & $55(78.6)$ & $39(83.0)$ & 0.065 \\
& No & $15(37.5)$ & $15(21.4)$ & $8(17.0)$ & \\
Urinary infection, $\mathbf{n}(\boldsymbol{\%})$ & Yes & $19(47.5)^{\mathrm{a}}$ & $56(80.0)^{\mathrm{b}}$ & $41(87.2)^{\mathrm{b}}$ & $<\mathbf{0 . 0 0 1}$ \\
& No & $21(52.5)$ & $14(20.0)$ & $6(12.8)$ & \\
\hline
\end{tabular}

Each superscript letter denotes difference between groups significantly from each other at the 0.05 level. (b>a). 
Table 3. Quality rates of SUI, UUI and MUI

\begin{tabular}{lcccc}
\hline & $\begin{array}{c}\text { UUI } \\
(\mathbf{n = 4 0})\end{array}$ & $\begin{array}{c}\text { SUI } \\
(\mathbf{n = 7 0})\end{array}$ & $\begin{array}{c}\text { MUI } \\
(\mathbf{n = 4 7})\end{array}$ & p value \\
\hline UDI-6 total & $10.85 \pm 2.66^{\mathrm{a}}$ & $11.49 \pm 2.18^{\mathrm{a}}$ & $13.43 \pm 1.90^{\mathrm{b}}$ & $<\mathbf{0 . 0 0 1}$ \\
Irritative & $3.73 \pm 1.26^{\mathrm{a}}$ & $4.59 \pm 1.06^{\mathrm{b}}$ & $4.66 \pm 0.76^{\mathrm{b}}$ & $<\mathbf{0 0 1}$ \\
Stress & $4.05 \pm 0.99^{\mathrm{b}}$ & $3.43 \pm 1.07^{\mathrm{a}}$ & $4.34 \pm 1.07^{\mathrm{b}}$ & $<\mathbf{0 . 0 0 1}$ \\
Obstructive & $3.08 \pm 1.23^{\mathrm{a}}$ & $3.49 \pm 1.06^{\mathrm{a}}$ & $4.43 \pm 1.04^{\mathrm{b}}$ & $<\mathbf{0 0 1}$ \\
IIQ-7 total & $11.45 \pm 3.92^{\mathrm{a}}$ & $13.26 \pm 2.60^{\mathrm{b}}$ & $16.06 \pm 2.44^{\mathrm{c}}$ & $<\mathbf{0 . 0 0 1}$ \\
Physical activity & $3.40 \pm 1.37^{\mathrm{a}}$ & $3.81 \pm 0.84^{\mathrm{a}}$ & $4.66 \pm 1.01^{\mathrm{b}}$ & $<\mathbf{0 . 0 0 1}$ \\
Travel & $2.63 \pm 0.63^{\mathrm{a}}$ & $2.89 \pm 0.36^{\mathrm{b}}$ & $2.96 \pm 0.20^{\mathrm{b}}$ & $<\boldsymbol{0 . 0 0 1}$ \\
Social & $2.60 \pm 1.15^{\mathrm{a}}$ & $3.19 \pm 0.94^{\mathrm{b}}$ & $4.04 \pm 1.06^{\mathrm{c}}$ & $<\mathbf{0 0 1}$ \\
Emotional & $2.80 \pm 1.24^{\mathrm{a}}$ & $3.36 \pm 1.06^{\mathrm{b}}$ & $4.36 \pm 0.92^{\mathrm{c}}$ & $<\boldsymbol{0 . 0 0 1}$ \\
\hline
\end{tabular}

Each superscript letter denotes difference between groups significantly from each other at the 0.05 level. (c>b>a).

\section{Discussion}

The results of the study showed that UI negatively affects the quality of life of women, although it is quite common. It also made us realize that they did not consult a doctor for this problem, which has an effective treatment. In the study, the prevalence of UI, risk factors and quality of life were evaluated according to UI types.

According to the study results, UI was detected in one third of the women in the family health center. This rate is quite variable in studies. In a previous cross-sectional study, it was shown lower prevalence among reproductive age women who had been admitted to an outpatient clinic with UI (14). Relatively high prevalence of UI was documented as $38.4 \%$ in a population-based study in Iran (15). The frequency of UI can vary greatly depending on where the study was performed, the region studied, and the participants. In a cross-sectional study performed by Danforth et al, a high prevalence of UI with increasing age was found (16). In a study performed in Norway, the prevalence among the 20-24 and 2529 year old age groups was $10 \%$ and $14 \%$, respectively (17). In similar to the literature, increased age was positively correlated with the presence of UI, in the present study.

In the study, less than half of patients referred to the doctor for this discomfort and requested treatment. Other patients with incontinence either do not mention these complaints to the doctor because they are embarrassed, or they consider it is normal at that age. In a study that focuses on how women feel in reality with the focus group study, it was observed that women developed strategies to cope on their own with reactions from their spouses and the environment (18). Shyness and cultural retreat play an important role in this and also with the belief that UI is a normal situation caused by increasing age. In a large multi-centered study, only one third of women had consulted a doctor about their UI symptoms (19). Ueda et al. states that only $3 \%$ of patients had ever consulted doctors because of their urinary complaints while one fourth determined their condition as a disease (20).

In our study, it was found a positive correlation between UI and weight, a young age with the first pregnancy, constipation, type of delivery, UTI's, presence of family incontinence history, and menopause. Studies performed in such centers reported that obesity (21), positive family history, and vaginal delivery (22), UTI's (23), constipation and menopause (24) were associated with UI as risk factors.

It was determined that SUI was more common than other types of UI in the study. In such studies, SUI was also determined as the most common type of UI $(25,26,27)$. There are also publications in the literature observing MUI and UUI incontinence is seen more $(28,29)$. The reason for this difference may be the age ranges in the studies.

In the present study, UDI-6 and IIQ-7 scores were higher in the SUI group when compared to the UUI group. Both the UDI-6 and IIQ-7 scores were significantly higher in the MUI group than both SUI and UUI. Similarly, Dooley et al found that women with MUI reported greater incontinence than women with either pure stress or UI (30). Coyne et al reported no significant difference according to quality of life measures, between the three incontinence groups UUI, SUI, and MUI, but also added that because of the lower rates of incontinence episodes, patients with SUI can adapt their lifestyles by avoiding heavy lifting and exercising, and thus prevent situations that lead to involuntary loss of urine (28). Lasserre et al (14) stated that longer duration of symptoms cause higher frequency of comorbid urinary symptoms among women with MUI.

\section{Limitations}

The present study has a limitation that determining the type of UI in patients was based on their answers to questions about the symptoms of UI. Despite the 
questionnaire used for this study was clinically valid and consistent with the definitions declared in the International Continence Society, no urodynamic test was carried out on the participants to verify the type of UI. Another limitation of the study is that the results cannot be generalized.

\section{Conclusions}

In conclusion, the incidence of urinary incontinence in our study was consistent with the ranges reported in the literature. In our study, we have observed that SUI makes life more difficult than UUI, besides; MUI have worst life impact on the quality of life than the other two types. It is thought that physicians should question this issue more carefully when taking anamnesis due to the low rate of the patients' help-seeking behaviors. First of all family physicians (FP) should encourage the patients' to share all their complaints and discomforts easily. The incidence of UI may be greater in the outpatient clinics than previously thought and FP's should be aware of this uncomfortable condition in their patients.

Ethics Committee Approval: Appropriate permission for the study was obtained from the Committee of Ethics of Ataturk University (approval no: B.30.2.ATA.0.01.00/119).

Peer-review: Externally peer-reviewed.

\section{Author Contributions:}

Concept: Z.G, Y.Ç, Design: Z.G, Y.Ç, Literature Search: A.E.K, Y.Ç, A.E.K, Data Collection and Processing: Z.G, Y.Ç, M.A.S, Analysis or Interpretation: A.E.K, Writing: Z.G, Y.Ç, M.A.S., A.E.K.,

Conflict of Interest: No conflict of interest was declared by the author.

Financial Disclosure: The author declared that this study hasn't received no financial support.

\section{References}

1. Haylen BT, de Ridder D, Freeman RM, Swift SE, Berghmans $\mathrm{B}$, Lee $\mathrm{J}$, et al. International Urogynecological Association; International Continence Society. An International Urogynecological Association (IUGA)/International Continence Society (ICS) joint report on the terminology for female pelvic floor dysfunction. Neurourol Urodyn 2010; 29(1): 4-20.
2. Irwin DE, Milsom I, Hunskaar S, Reilly K, Kopp Z, Herschorn S, et al. Population-based survey of urinary incontinence, overactive bladder, and other lower urinary tract symptoms in five countries: results of the EPIC study. Eur Urol 2006; 50(6): 1306-1314.

3. Milsom I, Gyhagen M. Epidemiology (Europe). In: Cardozo L, Staskin D. Editors, Textbook of Female Urology and Urogynaecology. Boca Raton: CRC Press; 2017

4. Baykuş N, Yenal K. Prevalence of urinary incontinence in women aged 18 and over and affecting factors. J Women Aging 2019; 22: 1-13.

5. Kılıç M. Prevalence and risk factors of sexual dysfunction in healthy women in Turkey. Afr Health Sci 2019; 19(3): 2623-2633.

6. Biyik I, Kucuk B, Arpaci HF, Demirci H. Factors affecting doctor visits of postmenopausal women with urinary incontinence. Low Urin Tract Symptoms 2019; 11(4): 200-205.

7. Ozdurak İ, Goymen A, Simsek Y, Ozakin E , Akpak Y, Şık A, Sarı O . Impacts of Childbirth on the Subsequent Risk of Stress Urinary Incontinence. Konuralp Medical Journal 2018; 10(2): 149-152.

8. Goforth J, Langaker M. Urinary Incontinence in Women. N C Med J 2016; 77(6): 423-425

9. Steibliene V, Aniuliene R, Aniulis P, Raskauskiene N, Adomaitiene V. Affective Symptoms and Health-Related Quality of Life Among Women with Stress Urinary Incontinence: Cross-Sectional Study. Neuropsychiatr Dis Treat 2020; 24; 16: 535-544.

10.Pal M, Halder A, Bandyopadhyay S. Approach to a woman with urinary incontinence. Urol Ann 2020; 12(1): 4-8.

11.Schreiber Pedersen L, Lose G, Høybye MT, Jürgensen $M$, Waldmann A, Rudnicki $M$. Predictors and reasons for help-seeking behavior among women with urinary incontinence. Int Urogynecol J 2018; 29(4): 521-530.

12.Nusee Z, Rusly A, Jamalludin AR, Abdulwahab DF, Ismail R. Translation and Validation of Bahasa Malaysia Version of Urogenital Distress Inventory (UDI-6) and Incontinence Impact Quality of Life Questionnaires (IIQ-7), a Cross Sectional Study. Malays J Med Sci 2016; 23(3): 57-63.

13.Cam C, Sakalli M, Ay P, Cam M. Validation of the short forms of the incontinence impact questionnaire (IIQ-7) and the urogenital distress inventory (UDI-6) in a Turkish population. Neurourol Urodyn 2007; 26(1): 129-133. 
14.Lasserre A, Pelat C, Guéroult V, Hanslik T, Chartier-Kastler E, Blanchon $\mathrm{T}$, et al. Urinary incontinence in French women: prevalence, risk factors, and impact on quality of life. Eur Urol 2009; 56(1): 177-183.

15.Ahmadi B, Alimohammadian M, Golestan B, Mahjubi B, Janani L, Mirzaei R. The hidden epidemic of urinary incontinence in women: a population-based study with emphasis on preventive strategies. Int Urogynecol J 2010; 21 (4): 453-459.

16.Danforth KN, Townsend MK, Lifford K, Curhan GC, Resnick NM, Grodstein F. Risk factors for urinary incontinence among middle-aged women. Am J Obstet Gynecol 2006; 194(2): 339-445.

17. Komeilifar R, Javadifar N, Afshari P, Haghighizade MH, Honarmandpour A. The Prevalence, Subtypes and Obstetric Risk Factors of Urinary Incontinence in Reproductive Age Women Referred to Community Health Care Centers of Dezful, Iran- 2015. Int J Community Based Nurs Midwifery 2017; 5(3): 275-283.

18. Bascur-Castillo C, Araneda-Gatica V, CastroArias H, Portino MC. Determinants in the process of seeking help for urinary incontinence in the Chilean health system. Int J Gynaecol Obstet 2019; 144(1): 103-111.

19. O'Donnell M, Lose G, Sykes D, Voss S, Hunskaar S. Help-seeking behaviour and associated factors among women with urinary incontinence in France, Germany, Spain and the United Kingdom. Eur Urol 2005; 47(3): 385-392.

20.Ueda T, Tamaki M, Kageyama S, Yoshimura N, Yoshida O. Urinary incontinence among community-dwelling people aged 40 years or older in Japan: prevalence, risk factors, knowledge and self-perception. Int J Urol 2000; 7(3): 95-103.

21.Subak LL, Richter HE, Hunskaar S. Obesity and urinary incontinence: epidemiology and clinical research update. J Urol 2009; 182(6): 2-7.

22.Torrisi G, Minini G, Bernasconi F, Perrone A, Trezza G, Guardabasso V, et al. A prospective study of pelvic floor dysfunctions related to delivery. Eur J Obstet Gynecol Reprod Biol 2012; 160 (1): 110-115.

23.Liu B, Wang L, Huang SS, Wu Q, Wu DL. Prevalence and risk factors of urinary incontinence among Chinese women in Shanghai. Int J Clin Exp Med 2014; 7(3): 686-696.

24.Sensoy N, Dogan N, Ozek B, Karaaslan L. Urinary incontinence in women: prevalence rates, risk factors and impact on quality of life. Pak $\mathbf{J}$ Med Sci 2013; 29 (3): 818-822.
25.Xu C, Chen M, Fu J, Meng Y, Qin S, Lou Y, et al. Urinary incontinence status and risk factors in women aged 50-70 years: a cross-sectional study in Hunan, China. Int Urogynecol J 2020; 24.doi: 10.1007/s00192-020-04259-8.

26.Jokhio AH, Rizvi RM, Rizvi J, MacArthur C. Urinary incontinence in women in rural Pakistan: prevalence, severity, associated factors and impact on life. BJOG 2013; 120 (2): 180-186.

27.Herschorn S, Gajewski J, Schulz J, Corcos J. A population-based study of urinary symptoms and incontinence: the Canadian Urinary Bladder Survey. BJU Int 2008; 101 (1): 52-58.

28. Coyne KS, Zhou Z, Thompson C, Versi E. The impact on health-related quality of life of stress, urge and mixed urinary incontinence. BJU Int 2003; 92 (7): 731-735.

29.Ng KL, Ng KWR, Thu WPP, Kramer MS, Logan $\mathrm{S}$, Yong EL. Risk factors and prevalence of urinary incontinence in mid-life Singaporean women: the Integrated Women's Health Program. Int Urogynecol J 2019; 28.doi: 10.1007/s00192019-04132-3.

30.Dooley Y, Lowenstein L, Kenton K, FitzGerald MP, Brubaker L. Mixed incontinence is more bothersome than pure incontinence subtypes. Int Urogynecol J Pelvic Floor Dysfunct 2008; 19(10): 1359-1362. 